
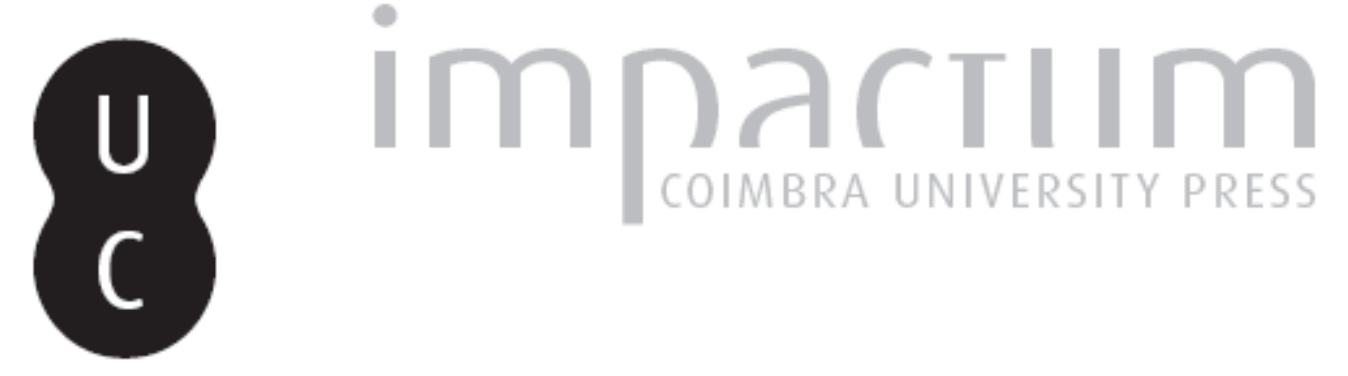

\title{
Sobre a utilidade da teoria na historiografia: mobilidade de conceitos e história comparada dos regimes políticos no século $\mathrm{XX}$
}

Autor(es): $\quad$ Nunes, João Paulo Avelãs

Publicado por: Imprensa da Universidade de Coimbra

URL persistente:

URI:http://hdl.handle.net/10316.2/43249

DOI:

DOI:https://doi.org/10.14195/0870-4147_48_13

Accessed : $\quad$ 26-Apr-2023 13:27:01

A navegação consulta e descarregamento dos títulos inseridos nas Bibliotecas Digitais UC Digitalis, UC Pombalina e UC Impactum, pressupõem a aceitação plena e sem reservas dos Termos e Condições de Uso destas Bibliotecas Digitais, disponíveis em https://digitalis.uc.pt/pt-pt/termos.

Conforme exposto nos referidos Termos e Condições de Uso, o descarregamento de títulos de acesso restrito requer uma licença válida de autorização devendo o utilizador aceder ao(s) documento(s) a partir de um endereço de IP da instituição detentora da supramencionada licença.

Ao utilizador é apenas permitido o descarregamento para uso pessoal, pelo que o emprego do(s) título(s) descarregado(s) para outro fim, designadamente comercial, carece de autorização do respetivo autor ou editor da obra.

Na medida em que todas as obras da UC Digitalis se encontram protegidas pelo Código do Direito de Autor e Direitos Conexos e demais legislação aplicável, toda a cópia, parcial ou total, deste documento, nos casos em que é legalmente admitida, deverá conter ou fazer-se acompanhar por este aviso.

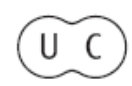




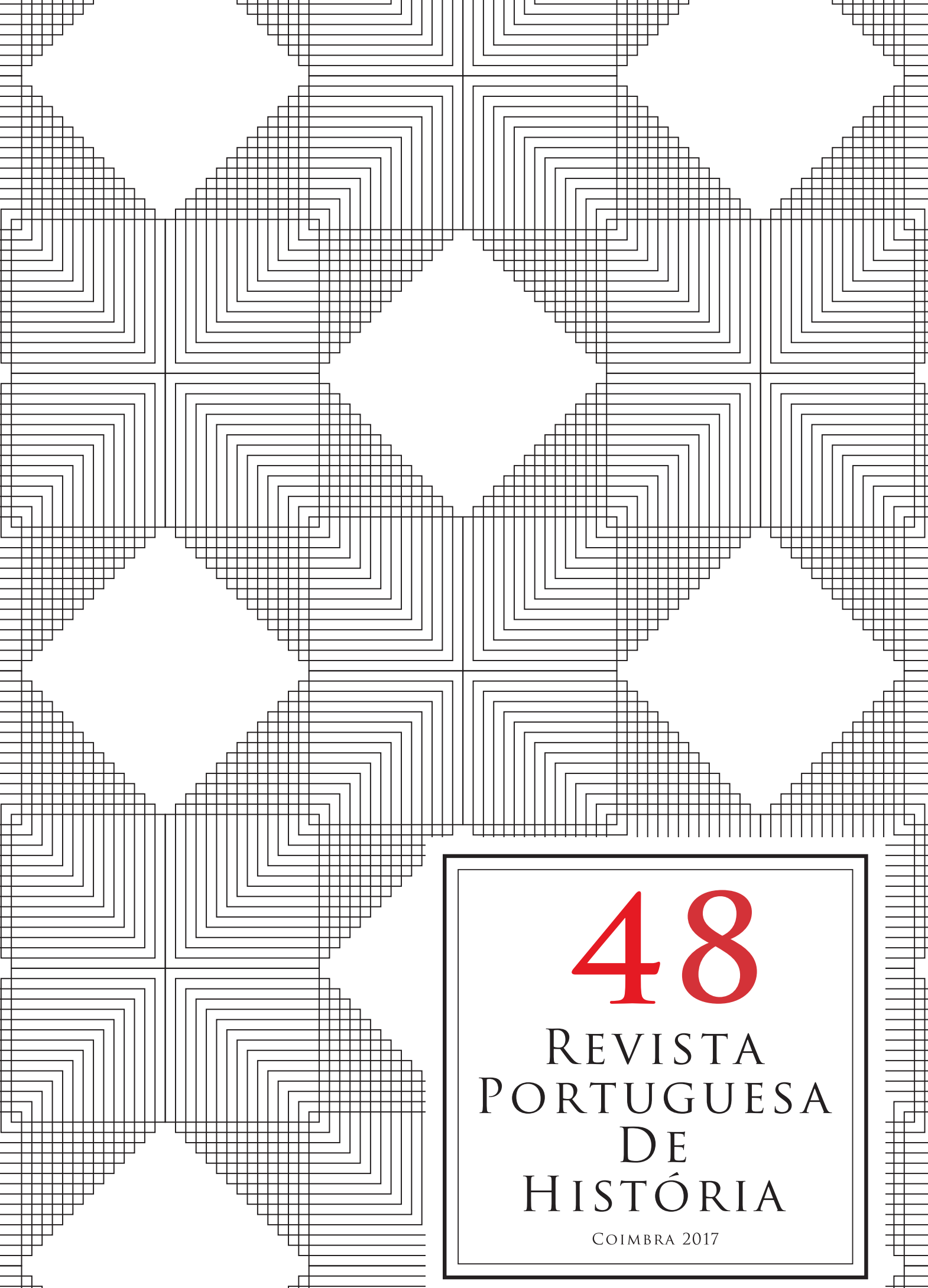




\title{
Sobre a utilidade da teoria na historiografia: mobilidade de conceitos e história comparada dos regimes políticos no século $\mathrm{XX}^{*}$
}

\author{
On the usefulness of theory in historiography: \\ the mobility of concepts and compared history \\ of 20th century political regimes
}

\author{
Jỗo Paulo Avelãs Nunes \\ DHEEAA/FLUC e CEIS20/UC \\ jpavelas@fl.uc.pt
}

Texto recebido em/Text submitted on: 11/10/2016

Texto aprovado em/Text approved on: 19/05/2017

Resumo:

Procurando contrariar uma tendência de hostilidade ao debate teórico que, em parte, marcaria a historiografia em geral e a historiografia portuguesa em particular, reflete-se, neste texto, sobre o modo como os paradigmas epistemológicos vigentes ao longo da época contemporânea influenciaram as diversas correntes historiográficas; acerca das características da historiografia enquanto ciência e das características das tecnologias derivadas da historiografia; sobre as vantagens de se utilizarem conceitos teóricos, quer para interpretar a evolução da regionalidade política em Portugal e no Brasil ao longo do século XX, quer para comparar essas duas com outras experiências históricas nacionais.
Abstract:

Seeking to run counter the hostility trend against the theoretical discussion that would, in part, mark historiography in general and Portuguese historiography in particular, the present paper addresses how the epistemological paradigms existing in the contemporary era influenced different historiographic currents; the characteristics of historiography as a science and that of the technologies derived from historiography; the advantages of using theoretical concepts, either to interpret the development of political regionality in Portugal and Brazil in the 20th century, or to compare the two with other national historical experiences.

* Artigo resultante da adaptação dos textos da Conferência O Estado Novo português: solução inevitável?, do texto da intervenção na Mesa Redonda "Os fascismos e os Estados Novos", do roteiro do Mini-Curso Estado Novo, autoritarismo e totalitarismo, assegurados no âmbito do Colóquio Internacional Brasil/Portugal: ditaduras, transições e democracias (Santa Maria, Rio Grande do Sul, Brasil, 06/04/15-10/10/15). 
Quanto aos fenómenos políticos propriamente ditos, defende-se a operatividade de uma tipologia de regimes - das monarquias absolutas de direito divino e carácter corporativo às democracias - que permitirá abarcar o essencial das realidades empíricas ocorridas ao longo da época contemporânea, tanto em Portugal e no Brasil (na Europa do Sul e na América Latina em geral), como à escala global. Evocam-se, ainda, categorias teóricas potenciadoras da análise, por um lado, dos níveis de privação de direitos de participação política efetiva tendo em conta critérios de natureza étnica e/ ou religiosa; por outro, do modo como foram sendo configurados os sistemas de relações internacionais nos quais Portugal e o Brasil estiveram ou estão integrados.

Palavras-chave: Conceitos teóricos; Ciência; Tecnologia; Regimes políticos; História comparada.
As for political phenomena itself, it is argued that the operability of a typology of regimes - from absolute monarchies of divine right and corporate character to democracies - which will make it possible to address the empirical realities in the contemporary era in Portugal and Brazil (in Southern Europe and Latin America overall), and on a global scale. We also evoke theoretical categories that enhance, on the one hand, the analysis of the levels of deprivation of rights of effective political participation taking into account ethnic and/ or religious criteria; on the other hand, how the international relations systems in which Portugal and Brazil were or are integrated are being configured.

Keywords: Theoretical concepts; Science; Technology; Political regimes; Compared history. 
Sobre a utilidade da teoria na historiografia: mobilidade de conceitos e história comparada

\section{Introdução $^{1}$}

Pelo menos em Portugal - e, eventualmente, no Brasil -, a historiografia será, talvez, a ciência social na qual menos relevância se atribui às questões teóricas. Ao contrário da economia e da geografia, da sociologia e da antropologia, da psicologia e da linguística, a historiografia (a história, a arqueologia e a história da arte) procuraria abarcar a totalidade da experiência humana no espaço e no tempo; privilegiaria as transformações em alternativa às permanências, as sequelas das intervenções individuais em alternativa às implicações das ações coletivas. Daí resultaria a inutilidade de aplicar modelos globalizantes, de procurar encontrar continuidades universais numa realidade tida como intrinsecamente fracionada, decorrente de mudanças tantas vezes aleatórias.

Muitos historiadores consideram, mesmo, que um aparato teórico é, quase sempre, um obstáculo ao estabelecimento de relações deontologicamente corretas entre sujeito e objeto de estudo; uma forma encapotada de subordinar a atividade de produção, divulgação e aplicação de conhecimento a uma determinada agenda ideológica. Para serem objetivos e operatórios, os investigadores, professores e outros técnicos com formação em história deveriam focalizar-se, quer nos aspetos metodológicos, quer na reconstituição e análise de dados empíricos; deveriam deixar-se surpreender pelas especificidades diferenciadoras de cada vetor e de cada etapa da realidade em observação.

Face, quer à extrema complexidade das temáticas abordadas pela historiografia, quer ao inultrapassável correlacionamento entre os atores históricos e os investigadores, quaisquer tentativas de interpretar e comparar sociedades humanas partindo de conceitos teóricos tendencialmente universais e intemporais teria resultado e continuaria a implicar a elaboração de discursos sobretudo ideológicos. Ideológicos porque apriorísticos e generalistas ou vagos, ignorando muita da pluralidade e das contradições próprias das sociedades humanas. Ideológicos porque antes de mais empenhados em utilizar vestígios

\footnotetext{
${ }^{1}$ Cfr., nomeadamente, Guy Bourdé e Hervé Martin, As escolas históricas (trad. do francês), Mem Martins, Publicações Europa-América, 1990; Fernando Catroga, Memória, história e historiografia, Coimbra, Quarteto Editora, 2001; Fazer história (trad. do francês), 3 volumes, Amadora, Livraria Bertrand, 1977-1987; Marc Ferro, L'histoire sous surveillance. Science et conscience de l'histoire, Paris, Calman-Lévy, 1985; Adérito Sedas Nunes, "Questões preliminares sobre as ciências sociais", Análise Social, vol. VIII, n. ${ }^{\circ}$ 30/31, 1970, p. 201-298; Revista de História Jerónimo Zurita, n. ${ }^{\circ}$ 71, 1995, p. 4-345 ("La historiografia en el horizonte del año 2000”); Luís Reis Torgal, História e ideologia, Coimbra, Livraria Minerva, 1989; Enzo Traverso, O passado, modos de usar (trad. do francês), Lisboa, Edições Unipop, 2012.
} 
avulso da realidade para legitimar certas leituras acerca da e determinadas propostas de intervenção na mesma.

Hegemónicas durante o longo período de predomínio do "paradigma moderno" - consubstanciado em correntes historiográficas como as 'escolas' metódica, historicista ou romântica, positivista, marxista, irracionalista providencialista, historicista neo-metódica -, questionadas pelos proponentes do "paradigma neo-moderno" - idealistas críticos, protagonistas da história institucional e política clássica, da história económica e social clássica, da história nova, da história estruturalista, marxistas críticos - e uma vez mais assumidas pelos cultores do "paradigma pós-moderno" - nova história económica, historiografia neo-narrativista -, as ideias em causa mantiveram uma influência ainda maior nos âmbitos do ensino, da formação e da divulgação da história.

Viso, assim, neste artigo, contraditar muitas das conceções antes sintetizadas e, de alguma forma, com influência significativa no Portugal atual (talvez também no Brasil). Adoto os fundamentos do "paradigma neo-moderno"; os pressupostos deontológicos e epistemológicos da história nova. Defendo que, à semelhança de todas as outras ciências, a historiografia pode gerar conhecimento objetivante acerca das temáticas que circunscreve. Deve-se, para o efeito, limitar e/ou mobilizar os componentes ideológicos em presença recorrendo a pressupostos deontológicos e epistemológicos, a conceitos e a metodologias operatórios; concretizando tarefas de reconstituição de dados empíricos e de interpretação. Para além dos historiadores, também os outros cientistas e as sociedades em geral são responsáveis por gerar um ambiente de debate científico, cultural e cívico que promova, em cada momento, o aprofundamento do "máximo de conhecimento possível".

Dada a importância dos fenómenos político-institucionais, tendo em conta a natureza simultaneamente nacional e global da regionalidade em causa, perante as respetivas implicações ideológicas nos nossos dias, assumo que a história dos regimes políticos no século XX é uma amostra pertinente quando se pretende argumentar acerca das virtualidades da ligação entre reflexão teórica e atividade historiográfica. Focalizo a atenção nos casos português e brasileiro, Estados semiperiféricos ou periféricos marcados pela presença de soluções demoliberais e democráticas, mas, também, de figurinos ditatoriais (autoritários e/ou totalitários) e de processos de transição. 
Sobre a utilidade da teoria na historiografia:

mobilidade de conceitos e história comparada

dos regimes politicos no século $X X$

\section{Conceitos teóricos e paradigmas epistemológicos ${ }^{2}$}

Parto do princípio de que, ao longo da época contemporânea e até ao momento, as sociedades ocidentais e ocidentalizadas geraram três modalidades nucleares de produção, caracterização e valoração da cultura erudita: o "paradigma moderno", o "paradigma pós-moderno" e o "paradigma neo-moderno". Estruturado ainda no Antigo Regime (entre o Renascimento e os séculos XVII/XVIII) mas tendo atingido a hegemonia nos séculos XIX e XX, o "paradigma moderno" proclamou a especificidade, autonomia e superioridade do conhecimento científico e tecnológico, adjetivado como objetivo, neutro e equivalente à realidade porque baseado numa permanente aferição teórica e metodológica. Afirmou, ainda, a capacidade da ciência e da tecnologia para, no médio prazo, encontrar formas de resolver o essencial dos problemas decorrentes do relacionamento entre os seres humanos e a natureza; as vantagens de pautar a governação das comunidades humanas pela "aplicação das descobertas da ciência".

Lembro, a este último propósito, que a generalidade das grandes mundividências e correntes ideológicas da época contemporânea se apresentaram como cientismos, ou seja, enquanto propósitos universalmente válidos e verdades indiscutíveis por derivarem diretamente de "conclusões científicas". Associando maiores ou menores graus de intolerância, detetam-se as citadas características, por exemplo, no darwinismo social, no nacionalismo e no internacionalismo; no liberalismo, no positivismo, no socialismo, na democracia cristã e no fascismo. As derivas autoritárias e totalitárias de muitos destes cientismos, os problemas sociais e ambientais entretanto agravados, as potencialidades reafirmadas por outros saberes contribuíram, precisamente, para a crise do "paradigma moderno" e para o eclodir da "rutura pós-moderna".

Emergente na segunda metade da década de 1960, o "paradigma pós-moderno" surge, pois, enquanto reação aos bloqueios e insucessos do

${ }^{2}$ Cfr., entre outros, Maria de Fátima Bonifácio, "O abençoado retorno da velha história", Análise Social, vol. XXVIII, n. ${ }^{\circ}$ 122, 1993 (3. ${ }^{\circ}$ ), p. 623-630; Fernando Catroga, "Caminhos do fim da história", Revista de História das Ideias, vol. 23, 2002, p. 131-234; António Manuel Hespanha, "História e sistema: interrogações à historiografia pós-moderna", Ler História, n. ${ }^{0} 9$, 1986, p. 65-84; Frederic Jameson, Posmodernism or the cultural logic of late capitalism, Durham, Duke University Press, 1991; João Paulo Avelãs Nunes, “Tipologias de regimes políticos. Para uma leitura neo-moderna do Estado Novo e do Nuevo Estado", População e Sociedade, n. ${ }^{\circ}$ 8, 2002, p. 73-101; Boaventura Sousa Santos, Introdução a uma ciência pós-moderna, Porto, Edições Afrontamento, 1989; Gianni Vattimo, O fim da modernidade. Niilismo e hermenêutica na cultura pós-moderna, Lisboa, Editorial Presença, 1987. 
"paradigma moderno": insuficiente complexidade epistemológica, arrogância e isolamento face a outros saberes, disponibilidade para a instrumentalização político-ideológica. Seria, aparentemente, uma crítica radical às funções desempenhadas pela cultura erudita no âmbito da economia-mundo capitalista. Estar-se-á, no entanto, provavelmente, face a um fenómeno mais complexo. Quer a vertente mais subjetivista ou irracionalista, quer a componente neo-empirista da pós-modernidade acabam por assumir a inviabilidade ou a ilegitimidade de qualquer tentativa de interpretação e de transformação estrutural da realidade social, o que redunda no aceitar da reprodução do atual equilíbrio civilizacional (predomínio da cultura de massas, do capitalismo pós-keynesiano globalizado, de um sistema de relações internacionais multipolar, mas mais unilateral do que multilateral).

Menos facilmente identificável, o esforço de apresentação do "paradigma neo-moderno" (anos 1990) pretendeu contestar os aspetos encarados como negativos no "paradigma moderno" e, em simultâneo, recusar os excessos subjetivistas e empiristas do "paradigma pós-moderno". Tem-se pugnado pelo reconhecimento da importância do debate deontológico e epistemológico, teórico e metodológico, cultural e cívico; das potencialidades e das limitações do conhecimento científico e tecnológico, apenas capaz de esforços de objetivação e de operatividade temporária e parcialmente válidos; das identidades próprias e da utilidade social dos outros saberes; das implicações sociais negativas ou dramáticas de muitos dos cientismos; das sequelas mistificadoras, quer do niilismo subjetivista, quer da pretensa neutralidade/objetividade do neo-empirismo.

No que concerne à historiografia, a respetiva periodização difere, em parte, daquela que é proposta, em termos globais, para os paradigmas epistemológicos. Se, por um lado, se verifica uma coincidência temporal quanto ao "paradigma moderno" - o qual esteve na base das correntes metódica, historicista ou romântica, positivista, marxista, irracionalista providencialista e historicista neo-metódica -, o mesmo não aconteceu com a pós-modernidade e com a neo-modernidade. Decorrentes do que viria a ser "paradigma neo-moderno", o idealismo crítico, o marxismo crítico, a história institucional e política clássica, a história económica e social clássica, a história nova e a história estruturalista surgem a partir da década de 1930. Contestam aspetos nucleares das "historiografias modernas" antes mesmo da "rutura pós-moderna". Por sua vez, a nova história económica e a historiografia neo-narrativista, tributárias do "paradigma pós-moderno", opõem-se mais às "historiografias-neomodernas" do que às derivações do "paradigma moderno".

Complementarmente, parte substancial das 'escolas' historiográficas associadas aos vários paradigmas epistemológicos desvalorizou, mais do que 
Sobre a utilidade da teoria na historiografia: mobilidade de conceitos e história comparada dos regimes politicos no século $X X$

nas outras ciências (da natureza e sociais), a importância dos conceitos teóricos no esforço de produção de discursos objetivantes e operatórios sobre a realidade. Exceção feita ao positivismo, essa mesma tendência é, por definição, bastante marcada nas correntes associadas ao "paradigma moderno" e ao "paradigma pós-moderno". Mesmo as "historiografias-neomodernas" (salvo as correntes marxista crítica e estruturalista) acabaram por negligenciar a relevância do debate teórico. Salientam-se os exemplos da historiografia marxista - na qual, muitas vezes, a reflexão teórica foi substituída por exercícios retóricos de cariz ideológico - e da história nova, quase sempre timorata ou sincrética no que diz respeito à utilização de modelos abstratos de âmbito geral.

\section{Ciência, ideologia e interesses sociais ${ }^{3}$}

Adotando-se os pressupostos do "paradigma neo-moderno", o correlacionamento entre ciência e ideologia - na terminologia dos outros paradigmas epistemológicos, o correlacionamento entre "conhecimento objetivo e neutro" e interesses (individuais, grupais, organizacionais, nacionais, etc.) deixaria de ser encarado como um mal absoluto a limitar tanto quanto possível ("paradigma moderno") ou, na perspetiva do "paradigma pós-moderno", enquanto inevitabilidade a aceitar de forma não valorativa e apenas atenuável para determinadas vertentes da realidade, empiricamente acessíveis ou reconstituíveis através de modelos matemáticos. Algo de semelhante se aplicaria às características das e às ligações entre ciências e tecnologias, abandonando-se as perspetivas de que estas últimas seriam saberes indiscutíveis de aplicação necessária ou, em alternativa, instrumentos de controlo geradores de violência,

\footnotetext{
${ }^{3}$ Cfr., nomeadamente, Fernando Martins, "Historiografia, biografia e ética", Análise Social, n. ${ }^{\circ}$ 171, 2004, p. 391-408; José Mattoso, A Escrita da História. Teoria e Métodos, Lisboa, Editorial Estampa, 1988; João Paulo Avelãs Nunes, “A ‘boa propaganda', a 'má propaganda' e o ensino da História”, Revista Portuguesa de História, t. XXXIX, 2007, p. 165-182; João Paulo Avelãs Nunes, "O Estado, a historiografia e outras ciências/tecnologias sociais", João Paulo Avelãs Nunes e Américo Freire (coord.), Historiografias portuguesa e brasileira no século XX. Olhares cruzados, Coimbra, IUC, 2013, p. 53-79; João Paulo Avelãs Nunes, “A memória histórica enquanto tecnologia. Estado Novo, desenvolvimento e democracia”, Irene Flunser Pimentel e Maria Inácia Rezola (coord.), Democracia, ditadura: memória e justiça política, Lisboa, Edições Tinta da China, 2013, p. 363-384; João Paulo Avelãs Nunes, "Investigação historiográfica e ensino da História. Reflexões em didática da História a propósito das Metas Curriculares", Revista Portuguesa de História, t. 46, 2015, p. 487-507; Rui Ramos, "A causa da história do ponto de vista político", Penélope, n. ${ }^{\circ} 3$, 1991, p. 27-47; Martin Roberts (ed.), After de wall. History teaching in Europe (1989-2003), Hamburgo, Koerber Foundation, 2004; Luís Reis Torgal e outros, História da história em Portugal (séculos XIX-XX), Lisboa, Círculo de Leitores, 1996.
} 
nomeadamente quando baseados em modelos teóricos globalizantes e de matriz qualitativa.

Defendo, assim, que, por um lado, em termos abstratos, ciência e ideologia são categorias diferentes e quase incompatíveis. Enquanto a primeira visa produzir e divulgar conhecimento acerca da realidade, a segunda pretende conseguir apoio para uma determinada leitura sobre a mesma. Se para a ciência a aproximação ao objeto de estudo é essencial, na perspetiva da ideologia o fundamental está na competência para adquirir e manter apoios. Por outro lado, em todas as áreas científicas, qualquer sujeito de conhecimento só pode atuar se partir da sua visão idiossincrática, ou seja, do somatório das suas experiências, valores e conhecimentos. Reconhece-se, também, que, inúmeras vezes, não só os vetores ideológicos não impedem o conhecimento da realidade como estão na origem de avanços significativos em várias áreas de saber.

Perante um tal acréscimo dos graus de indefinição e de exigência inerentes ao universo da ciência, torna-se decisivo apostar no aprofundar da reflexão deontológica e epistemológica, teórica e metodológica, cultural e cívica, condição necessária para o reforço da capacidade de fazer, em cada momento e para cada problemática, as escolhas mais operatórias. Trata-se de gerar conhecimento o mais objetivante possível, temporariamente válido e adequado para a estruturação de soluções tecnológicas eficazes, fruto da combinação coerente de elementos culturais e ideológicos, de pressupostos deontológicos e epistemológicos, de conceitos e de métodos de investigação com origens mais ou menos diferentes. Implica uma abordagem interdisciplinar e não sistémica nem empirista, socialmente empenhada, mas não sectária. Decorre de um acrescido esforço para produzir aproximações à realidade numa etapa marcada pela implosão da generalidade das certezas herdadas do "paradigma moderno".

Relativamente às tecnologias de base científica, começo por salientar que podem ser geradas tanto a partir das ciências da natureza como das ciências sociais. Recuso, em seguida, as tentações cientistas, ou seja, quaisquer possibilidades de apresentação de hipóteses de solução para problemas sociais como caminhos únicos e inevitáveis porque baseados em conclusões científicas (absolutas e definitivas, neutras e benignas). Se, mau grado todas as limitações reconhecias e cautelas introduzidas, as ciências continuam a procurar conhecer a realidade, as tecnologias visam transformar o existente em algo diferente. Lidam, pois, intrinsecamente, quer com conhecimento científico estabilizado, quer com opções cívico-ideológicas (conceções, necessidades, interesses, avaliações de custo/benefício).

Evoco, a título ilustrativo, exemplos de tecnologias associadas ou relacionáveis com a historiografia, nomeadamente a didática e a divulgação 
Sobre a utilidade da teoria na historiografia: mobilidade de conceitos e história comparada dos regimes politicos no século $X X$

da história, o património cultural e a museologia, o planeamento do território e a gestão urbanística, a cultura organizacional e a publicidade/o marketing, o turismo e a animação culturais. Em todos estes - e em diversos outros - âmbitos de análise e de intervenção, deparamos com a presença, tanto de resultados da atividade de várias comunidades científicas, tecnológicas e de outros saberes (historiografia, psicologia, ciências da educação, sociologia, antropologia, ciência política, ciência da informação, ciências da comunicação, geografia, economia e gestão, engenharias, arquitetura, turismo, etc.), como de formas diferentes ou alternativas de encarar, nomeadamente, os indivíduos e as sociedades, os sistemas de ensino e o ensino da História, as memórias históricas e as identidades culturais, o património cultural e os museus, a utilização do território e a evolução dos espaços urbanos, as instituições públicas e as organizações privadas.

Em termos gerais e, de forma acrescida, à luz dos princípios do "paradigma neo-moderno", penso que a historiografia e as tecnologias dela derivadas dependem, para ampliar os respetivos níveis de objetivação e de operatividade, do reforço do debate teórico, isto é, da explicitação de procedimentos de utilização de conceitos e do considerar da relevância de um determinado conjunto de categorias para a análise de cada objeto de estudo. Assumo, finalmente, que um conceito é um instrumento teórico que tem por objetivos ajudar a reconstituir, entender e comparar objetos de estudo complexos - as problemáticas delimitadas e os respetivos enquadramentos -, não uma listagem exaustiva de características empíricas de presença supostamente obrigatória.

\section{Tipologia de regimes políticos ${ }^{4}$}

Correndo, embora, o risco de simplificar, adoto a proposta de periodização segundo a qual a época contemporânea teve início, antes de mais por influência da Holanda, da Inglaterra, dos EUA e de França, na segunda metade do

${ }^{4}$ Cfr., entre outros, Martin Blinkhorn (ed.), Fascists and conservatives, Londres, Unwin Hyman, 1990; Boris Fausto e Fernando J. Devoto, Brasil e Argentina. Um ensaio de história comparada (1850-2002), São Paulo, Editora 34, 2005, 2. ${ }^{\text {a }}$ edição; Jorge Ferreira e Lucília de Almeida Neves Delgado (org.), O Brasil republicano, 4 volumes, Rio de Janeiro, Editora Civilização Brasileira, 2003; António Manuel Hespanha, "Os modelos jurídicos do liberalismo, do fascismo e do Estado social. Continuidades e rupturas", Análise Social, vol. XXXVII, n. ${ }^{\circ} 165$, Inverno de 2003, p. 1285-1302; João Paulo Avelãs Nunes, "Tipologias de regimes políticos. Para uma leitura neo-moderna do Estado Novo e do Nuevo Estado", População e Sociedade, n. ${ }^{\circ}$ 8, 2002, p. 73-101; René Rémond, Introdução à história do nosso tempo (trad. do francês), Lisboa, Gradiva, 1994. 
século XVIII. Ocorreram, então, transformações profundas nos planos político, cultural, social e económico: emergência do liberalismo, do nacionalismo e do colonialismo; consolidação do predomínio do iluminismo e dos cientismos no âmbito da cultura erudita; estruturação de sociedades de classes, de burguesias e classes médias, operariados e campesinatos; industrialização, urbanização e afirmação da economia-mundo capitalista (com centros, semiperiferias e periferias).

Desde o século XVIII até aos nossos dias, face a condicionalismos nacionais e tendo em conta modalidades de integração em sistemas de relações internacionais, é possível identificar um grande número de situações diferentes no que à história política diz respeito. A tipologia de regimes políticos com a qual concordo viabiliza, precisamente, o agrupamento da enorme variedade inicial de realidades concretas num número limitado de categorias; a comparação dialética, não apenas funcional, entre objetos de estudo oriundos de vários espaços nacionais e conjunturas epocais; a elucidação do correlacionamento entre sistemas políticos e interesses sociais, entre equilíbrios nacionais e contextos internacionais.

Partindo dos figurinos políticos existentes nos séculos XV a XVIII, referem-se as monarquias absolutas de direito divino e carácter corporativo, os parlamentarismos plutocráticos e os despotismos esclarecidos. Enquanto o primeiro modelo enquadra a maioria das soluções vigentes durante a época moderna na Europa e na Ásia, o segundo corresponde às primeiras alternativas de cariz protoliberal, verificadas em países como a Holanda e a Inglaterra. Por sua vez, o terceiro conceito corresponde a tentativas de modernização parcelar e de reforço da eficácia dos aparelhos político-administrativos das monarquias absolutas sem alteração das suas próprias fontes de legitimidade e dos equilíbrios essenciais das sociedades de Antigo Regime.

Já em plena época contemporânea, inicialmente para a Europa e para a América, depois, à medida que ocorreram processos de autodeterminação e de independência, também para a Ásia e para África, propõem-se as categorias de liberalismo conservador, monarquia autocrática, demoliberalismo, autoritarismo, democracia e totalitarismo. A quase totalidade dos conceitos em apreço poderá ser cruzada com os modelos de "regime segregacionista" - o qual começou por ser designado como "regime de independência branca" por ter surgido associado ao estudo da República da África do Sul e da República da Rodésia - ou de "regime não segregacionista". Estas últimas duas categorias permitem considerar as situações em que os direitos de participação política efetiva são, ou não, (informal ou formal, parcial ou integralmente) negados tendo em conta argumentos de natureza étnica e/ou religiosa. 
Sobre a utilidade da teoria na historiografia: mobilidade de conceitos e história comparada dos regimes politicos no século $X X$

Numa abordagem superficial, dir-se-ia que, por terem origem nos revolucionários princípios liberais, os regimes liberais conservadores, demoliberais e democráticos seriam quase idênticos. Em sentido inverso, a ligação aos valores antiliberais tornaria semelhantes as monarquias autocráticas, os autoritarismos e os totalitarismos. Apesar de operatórios, os raciocínios em causa não devem levar a que se ignorem, quer vectores de diferenciação, quer outros elementos de caracterização, como a competição entre países, correntes e soluções políticas; a radicalização gerada por conflitos militares e por mudanças políticas violentas; as sequelas de crises económicas e sociais e da rivalidade entre grupos nacionais, étnicos e religiosos.

Fruto da aplicação e, ao mesmo tempo, da derrogação de muitos dos valores liberais, os regimes liberais conservadores implicaram, nomeadamente, a separação entre "cidadãos ativos", "cidadãos passivos" - mulheres, pobres, analfabetos - e "não cidadãos" (escravos e/ou outros seres humanos considerados "inferiores" segundo critérios "rácicos", "civilizacionais", médicos ou judiciais); o não reconhecimento de direitos políticos formais à maioria da população de cada país. Teriam, igualmente, acarretado a aparente limitação dos Estados às funções de soberania e de regulação jurídica preventiva ou coerciva; o agravamento dos níveis de precariedade que marcavam a vida dos indivíduos; a ilegalização e a repressão de grande parte das formas de organização socio-laboral das classes populares.

Decorrentes, por um lado, da argumentação e da combatividade dos excluídos pelos regimes liberais conservadores ou por soluções políticas antiliberais; por outro, das cedências negociadas por quem monopolizava o acesso formal ao poder político, os demoliberalismos e as democracias acarretam progressivos alargamentos de direitos, responsabilidades, mecanismos de enquadramento e modalidades de controlo. Ampliou-se ou universalizou-se e viabilizou-se a participação política formal; explicitaram-se mais direitos de cariz jurídico-político, económico, social e cultural; reforçaram-se as competências dos Estados e a dimensão das respetivas estruturas administrativas; reabilitaram-se as "sociedades-providência" e evoluiu-se no sentido da estruturação de "Estados-Providência"; legalizaram-se e integraram-se os sindicatos (no seguimento do que já acontecia com as organizações empresariais/patronais e com as associações de profissionais liberais).

À semelhança dos despotismos esclarecidos, o conceito de monarquia autocrática ajuda a compreender estratégias de transformação social global que, partindo de monarquias absolutas, procuram estruturar Estados-Nação capazes de competir com as novas soluções políticas (liberais conservadoras, demoliberais ou democráticas). Nessas etapas, a adoção de modelos político- 
-administrativos contemporâneos - "sociedades civis" e Parlamentos; Governos e Forças Armadas; sistemas judiciais e Forças Policiais; sistemas fiscais e aduaneiros; políticas económico-sociais e, por vezes, administrações coloniais; sistemas de investigação/ensino e políticas de memória/identidade (discursos historiográficos e comemorações histórico-patrióticas, monumentos e museus, estatuária e toponímia, etc.) - coexiste com a legitimação divina da soberania do monarca, com ausência de separação e de limitação constitucional do exercício dos poderes legislativo, executivo e judicial.

Uma vez que assumem uma natureza ditatorial, os regimes autoritários conservadores ou modernizadores; de direita, centro ou esquerda - pressupõem, explícita e formalmente, a privação de direitos político-jurídicos. Visam promover o regresso à "normalidade", interrompendo para o efeito situações tidas como massivamente disfuncionais; pretendem garantir a construção de novos equilíbrios, superando resistências encaradas como generalizadas. Impõem, pois, de forma temporária e parcial, tanto a reserva da capacidade de formulação de alternativas e de decisão para determinadas elites ou para segmentos mais amplos das populações dos países em causa, como a utilização de antigas e de novas modalidades de repressão (sobretudo punitiva) e de enquadramento.

Diferentemente, as ditaduras totalitárias - tradicionalistas, conservadoras e/ou modernizadoras; de extrema direita ou de extrema esquerda - implicam um diagnóstico prévio de ameaça total e continuada à sobrevivência das comunidades políticas em causa; a diabolização das conceções e práticas alternativas, apresentadas como sendo de origem estrangeira e maligna mas contando com apoios internos; a certeza quanto à validade absoluta do ideário proclamado, garantida pela ciência, pela filosofia, pela religião e/ou pelo senso comum. Prometem a "regeneração integral" dos Estados em apreço, a alcançar através da recuperação de soluções que no passado já teriam assegurado harmonia e grandeza ("utopias regressivas") e/ou da antecipação do concretizar de futuros pré-determinados.

Surgem, pois, os totalitarismos como respostas permanentes e definitivas - porque decorrentes da suposta identidade e das necessidades estruturais dos agregados humanos envolvidos (países e/ou nações, grupos étnicos e/ou religiosos, grupos sociais, etc.) - aos fatores de degradação (desagregação, subordinação, implosão) e/ou às potencialidades de realização plena (nos planos do sistema de relações internacionais, das relações interétnicas e inter-religiosas, das relações sociais, etc.) que teriam acompanhado os processos de construção da contemporaneidade. A justificação para o ampliar, qualitativo e quantitativo, dos níveis de enquadramento - neutralizador ou mobilizador - e de 
Sobre a utilidade da teoria na historiografia: mobilidade de conceitos e história comparada

repressão - preventiva e punitiva - decorreria dos graus de violência impostos pelos inimigos internos e externos, do carácter patológico das outras correntes ideológicas e das respetivas consequências, da obrigação e da urgência de fazer evoluir as sociedades no sentido supostamente demonstrado pelos vários saberes evocados.

Reconhecendo-se que as características dos regimes de matriz liberal e das ditaduras são substancialmente diferentes e, muitas vezes, opostas, será eficaz reconhecer as virtualidades de uma abordagem autónoma dos processos de transição e/ou de mudança revolucionária entre soluções políticas associadas a cada um dos referidos subuniversos. No que concerne à mutação de soluções de origem liberal para ditaduras, o conceito de transição deverá integrar, entre outras, variáveis como a cooptação por parte das elites tradicionais ou a intervenção militar; as estratégias de transformação explícitas e rápidas ou subliminares e lentas; a incorporação simultânea de propostas e de modalidades de intervenção de direita, centro e esquerda. Quanto às evoluções em sentido contrário, interessará considerar questões como a memória da violência e a "justiça transicional"; o grau de desmantelamento das estruturas ditatoriais e a sua substituição por figurinos liberais conservadores, demoliberais ou democráticos; a capacidade de os novos regimes se legitimarem e de ampliarem as respectivas bases sociais de apoio.

\section{Os casos português e brasileiro ${ }^{5}$}

No último quartel do século XIX e ao longo do século XX, Portugal e o Brasil conheceram sucessivas modalidades de configuração político-institucional, decorrentes dos respectivos equilíbrios sociais e tradições ideológico-organizacionais; das interações com outras Nações, nomeadamente

\footnotetext{
${ }^{5}$ Cfr., nomeadamente, Maria das Graças Ataíde de Almeida, A construção da verdade autoritária (1937-1945), São Paulo, USP/Humanidades, 2001; Fernando Catroga, "Transição e ditadura em Portugal nos primórdios do século XX", Rui Cunha Martins (coord.), Portugal 1974. Transição política em perspectiva histórica, Coimbra, IUC, 2011, p. 31-95; Manuel Braga da Cruz, O partido e o Estado no salazarismo, Lisboa, Editorial Presença, 1988; Gilvan Veiga Dockhorn, Quando a ordem é segurança e o progresso é desenvolvimento (1964-1974), Porto Alegre, EDIPUCRS, 2015; Gilvan Veiga Dockhorn, Saudades do futuro (1974-1985), Santa Maria, UFSM, 2015; Roger Grifin, The nature of fascism, Londres, Routledge, 1996, 3. a edição; Roger Griffin, Modernism and fascism, Nova Iorque, Palgrave Macmillan, 2007; Eric Hobsbawm, A era dos extremos. História breve do século XX (1914-1991) (trad. do inglês), Lisboa, Editorial Presença, 1996; Stephen J. Lee, The european dictatorships (1918-1945), Londres, Routledge, 1996, 9. a edição; Juan J. Linz, Totalitarian and authoritarian regimes, Londres, Lynne Rienner, 2000; Manuel Loff, "Los regímenes autoritarios", Ayer, n. ${ }^{\circ}$ 37, 2000, p. 125-162; Manuel Loff,
} 
com os Estados preponderantes no sistema de relações internacionais e com países vizinhos; das sequelas dos grandes conflitos militares (Primeira Grande Guerra, Guerra Civil de Espanha e Segunda Guerra Mundial, "Guerra

\footnotetext{
"O novo século é fascista!". O Mundo visto por Salazar e Franco (1936-1945), Porto, Campo das Letras, 2008; Manuel de Lucena, A evolução do sistema corporativo português, Lisboa, Perspectivas \& Realidades, vol. 1, 1976; João Madeira e outros, Vitimas de Salazar. Estado Novo e violência política, Lisboa, A Esfera dos Livros, 2007; Dalila Cabrita Mateus, A PIDE/DGS na guerra colonial (1961-1974), Lisboa, Terramar, 2004; João Paulo Avelãs Nunes, "Funções da legislação no Estado Novo português (1926-1974)", Estado, direito e ética. Ensaios sobre questões da nossa época, Nilson Borges Filho e Fernando Filgueiras (org.), Juiz de Fora, Granbery Edições, 2007, p. 31-50; João Paulo Avelãs Nunes, "Progresso, ordem, crise e regeneração: do Ultimato à Ditadura Militar", Biblos, 2. ${ }^{a}$ Série, vol. X, 2012, p. 117-130; João Paulo Avelãs Nunes, "A Primeira Grande Guerra, a emergência das massas e a (in)adaptação dos sistemas políticos", Revista Portuguesa de História, t. 45, 2014, p. 39-52; Richard Overy, Os ditadores. A Alemanha de Hitler e a Rússia de Estaline (trad. do inglês), Venda Nova, Bertrand Editora, 2005; Stanley G. Payne, Fascism: comparison and definition, Madison, University of Wisconsin Press, 1980; Stanley G. Payne, “'Fascism' or 'Bureaucratic authoritarianism'?”, Estudos de homenagem a A. H. de Oliveira Marques, Lisboa, Editorial Estampa, 1983, vol. II, p. 523-531; Stanley G. Payne, "Fascismo, modernismo, modernização", Penélope, n. ${ }^{\circ}$ 11, 1993, p. 85-102; Irene Flunser Pimentel, A história da PIDE, Lisboa, Temas \& Debates, 2007; António Costa Pinto, O salazarismo e o fascismo, Lisboa, Editorial Estampa, 1992; António Costa Pinto, Os Camisas Azuis. Ideologia, elites e movimentos fascistas em Portugal (1914-1945), Lisboa, Editorial Estampa, 1994; António Costa Pinto e Nuno Severiano Teixeira (coord.), A Primeira República entre o liberalismo e o autoritarismo, Lisboa, Edições Colibri, 2000; António Costa Pinto (dir.), Portugal contemporâneo (trad. do inglês), Madrid, Edições Sequitur, 2000; António Costa Pinto (coord.), Rethinking the nature of fascism: comparative perspectives, Nova Iorque, Palgrave Macmillan, 2010; António Costa Pinto (org.), Governar em ditadura. Elites e decisão política nas ditaduras da era do fascismo, Lisboa, ICS, 2012; Dawn Linda Raby, Resistência antifascista em Portugal (1941-1974) (trad. do inglês), Lisboa, Edições Salamandra, 1990; Rui Ramos, A segunda fundação (1890-1926), José Mattoso (dir.), História de Portugal, Lisboa, Círculo de Leitores, 1994, vol. 6; Rui Ramos, "Foi a Primeira República um regime liberal?", Manuel Baiôa (ed.), Elites e poder: a crise do sistema liberal em Portugal e Espanha (1918-1931), Lisboa, Edições Colibri e CIDEHUS/UE, 2004, p. 185-246; Maria da Conceição Ribeiro, A polícia política do Estado Novo (1926-1945), Lisboa, Editorial Estampa, 1995; Fernando Rosas (coord.), O Estado Novo (1926-1974), José Mattoso (dir.), História de Portugal, vol. 7, Lisboa, Círculo de Leitores, 1994; Fernando Rosas, "O salazarismo e o homem novo: ensaio sobre o Estado Novo e a questão do totalitarismo", Análise Social, n. ${ }^{\circ} 157,2001$, p. 1031-1054; Fernando Rosas e Maria Fernanda Rollo (coord.), História da Primeira República Portuguesa, Lisboa, Tinta da China, 2009; Fernando Rosas, Salazar e o poder: a arte de saber durar, Lisboa, Tinta da China, 2012; Henry Rousso (dir.), Stalinisme et nazisme. Histoire et mémoire comparées, Bruxelas, Éditions Complexe, 1999; António José Telo e Hipólito de la Torre Gómez, Portugal e a Espanha nos sistemas internacionais contemporâneos, Lisboa, Edições Cosmos, 2000; Luís Reis Torgal, Estados novos, Estado Novo: ensaios de história política e cultural, 2 volumes, Coimbra, IUC, 2009; Vasco Pulido Valente, "Revoluções: a «República Velha» (ensaio de interpretação política)", Análise Social, n. ${ }^{\circ}$ 115, 1992, p. 7-63.
} 
Sobre a utilidade da teoria na historiografia: mobilidade de conceitos e história comparada dos regimes politicos no século $X X$

Fria"). As permanências e as transformações verificadas em Portugal, na regionalidade em apreço, decorreram, ainda, do facto de, enquanto "metrópole" com "ilhas adjacentes", tutelar "territórios não autónomos" ("colónias" ou "províncias ultramarinas").

Podendo ser classificado como país semiperiférico ou de desenvolvimento intermédio, Portugal foi, no período em apreço, antes de mais influenciado por Espanha, pela Grã-Bretanha/Reino Unido e pela França, pela Alemanha e pelos EUA, pela Itália e pela Rússia/URSS. A Grã-Bretanha/Reino Unido (até 1939) e os EUA (a partir de 1945) desempenharam a função de potência dominante do sistema de relações internacionais e, nomeadamente, das zonas do globo relevantes para Lisboa. No essencial - apesar de algumas exceções -, Londres e Washington condicionaram e apoiaram as opções externas lusas sem interferir nas respetivas escolhas político-institucionais internas. Durante a Segunda Guerra Mundial, a Alemanha pretendeu substituir o Reino Unido e o Estado Novo de António de Oliveira Salazar procurou adaptar-se a essa possibilidade e/ou ameaça.

Enquanto país vizinho de maior dimensão, Espanha continuou a ser, até à integração de ambos os Estados na CEE/UE, um misto de parceiro cuja estabilidade interessava apoiar - por razões económico-financeiras, mas, essencialmente, para evitar que servisse de espaço de sustentação a organizações políticas portuguesas oposicionistas - e de ameaça de anexação ou de subordinação geoestratégica. A Alemanha (de 1871 a 1939), a Itália (de 1922 a 1943) e a Rússia/URSS (a partir de 1917) foram encarados como exemplos a seguir parcialmente em termos de organização política interna (Alemanha e Itália) ou como arquétipo de regime maligno (Rússia/URSS). Aparentando, embora, constituir a principal referência cultural e político-ideológica para as elites portuguesas, dada a sua posição secundária ao lado da Grã-Bretanha/ Reino Unido e dos EUA ("potências marítimas"), face ao seu perfil de "potência continental", a França adotou sempre um registo de complementaridade.

Após a "Crise de 1890/1891", no seguimento de décadas de vigência de um regime liberal conservador (depois de 1820, 1834 ou 1850/1851), será operatório considerar que Portugal passou a ter uma monarquia demoliberal com elementos de autoritarismo. As personalidades de D. Carlos I, João Franco e Mouzinho de Albuquerque, o Regicídio de 1908 e a tentativa de criar um partido político monárquico de massas, simbolizariam esse esforço de aumento de direitos de participação política formal, de mecanismos de regulação económica, de responsabilidades sociais do Estado, de possibilidades de organização socio-laboral. Acarretaram, por outro lado, a ampliação de modalidades administrativo-policiais e judiciais de controlo e repressão, a hostilização 
sistemática dos sectores republicanos e das correntes socialistas radicais, a recusa da evolução no sentido de um sistema político democrático.

Mau grado os indícios imediatos de modificação profunda - substituição da configuração monárquica pela republicana por intermédio da Revolução de 5 de Outubro de 1910, laicismo e anticatolicismo, retórica política e produção legislativa de cariz democratizante -, a Primeira República (1910-1926) manteve os traços fundamentais que justificam a utilização da categoria de regime demoliberal com vetores de autoritarismo. Assistiu-se, no essencial, ao prolongar de significativas limitações dos direitos de intervenção política formal; de mecanismos públicos e privados de controlo e repressão. Verificou-se, ainda, a segregação dos sectores monárquicos, católicos e socialistas radicais; a consolidação de aspirações, organizações e experiências autoritárias ou proto-totalitárias, com destaque para a radicalização à direita dos projetos de restauração monárquica (1910-1919), para o Integralismo Lusitano, para o "interregno sidonista" (1917-1919), para o emergir de organizações e de um frentismo de direita e de extrema-direita a partir da primeira metade da década de 1920.

Suspensa a Primeira República através do Golpe Militar e Civil de 28 de Maio de 1926, foi anunciada a adoção de uma solução ditatorial temporária e parcelar. O figurino autoritário, marcado pela instabilidade decorrente dos conflitos no interior da "situação" e com as oposições, visaria, apenas, aperfeiçoar o regime anterior: desmantelando a hegemonia da "fação democrática" e promovendo o reforço da posição de sectores conservadores, disciplinando o movimento sindical e normalizando as relações com a Igreja Católica, baixando os níveis da despesa pública e renegociando a dívida externa. Não pretenderia substituir a República demoliberal com traços de autoritarismo por um sistema político alternativo nem acusá-la de violentar o essencial da "identidade nacional".

Fragilizados pela incapacidade, tanto de alcançar os objetivos financeiros delimitados, como de impedir a eclosão de sublevações reviralhistas, os líderes da Ditadura Militar oriundos da "direita republicana" foram ultrapassados por António de Oliveira Salazar (Ministro das Finanças desde 1928, Presidente do Conselho a partir de 1932). Defensor de um projeto de ditadura permanente e integral, apresentado como regenerador de um Estado-Nação em profunda decadência devido à influência de conceções e de práticas tidas como malignas, patológicas e/ou estrangeiradas, contou com o apoio - ativo ou passivo - de muitos dos oficiais das Forças Armadas e das Forças Policiais; da Igreja e da "ação católica"; das organizações empresariais e das associações de profissionais liberais; do funcionalismo público; do campesinato do centro e norte de Portugal continental, dos Açores e da Madeira. 
Estruturado a partir de 1930, institucionalizado em 1933, o Estado Novo pode, assim, ser caracterizado como regime de tipo fascista, tendencialmente totalitário. Apesar dos relativamente baixos níveis de explicitação ideológica e jurídico-política, de violência policial e de irredentismo militar - explicáveis pelas características e escolhas dos chefes da ditadura, pela inexistência prévia de um partido político de massas de extrema-direita, pelos baixos níveis de mobilização política de grande parte da população portuguesa, pelo estatuto de pequeno país com desenvolvimento intermédio, pela integração na "zona de influência" do Reino Unido/França e, depois, dos EUA -, o salazarismo (antes e depois de 1945) e, mesmo, o marcelismo foram projetos sistémicos de controlo, repressão e reorganização do país - da "Metrópole" e das "Colónias" ou "Províncias Ultramarinas"; dos "colonos", dos "nativos", dos "assimilados" e dos "indígenas" - a partir do Estado e da "sociedade civil".

Salientam-se, a este propósito, a centralidade da figura do "Chefe" fundador do Estado Novo - António de Oliveira Salazar - e a natureza sobretudo cenográfica da Constituição de 1933. Destaca-se a importância das Forças Armadas, das Forças Policiais e do sistema de "justiça política", o qual incluiu a polícia política e os tribunais especiais, prisões especiais e locais de deportação; arbitrariedade e, depois, formalização jurídica da repressão preventiva e punitiva. Evoca-se a abrangência das estruturas envolvidas no esforço de enquadramento material e ideológico da população, antes de mais, os organismos de propaganda e de censura, a "educação nacional" e o património cultural, as obras públicas e a "organização corporativa". Refere-se a ampliação do grau de fusão entre o Estado e as instituições oficiosas do regime (Câmara Corporativa e União Nacional, Legião Portuguesa e Mocidade Portuguesa/Mocidade Portuguesa Feminina, etc.), a Igreja e a Ação Católica Portuguesa - implicando a extinção do partido democrata-cristão e dos sindicatos católicos, a perseguição dos "católicos progressistas" -, a generalidade das organizações da "sociedade civil" (socioprofissionais e assistenciais, culturais e desportivas, etc.).

Lembra-se, também, a prolongada recusa do regime português em aceitar elementos nucleares da evolução das sociedades centrais e semiperiféricas desde a Segunda Guerra Mundial (desde o início do fim da "época do fascismo"). Elencam-se, entre outros, o objetivo de derrotar o Terceiro Reich nacional-socialista e a emergência dos EUA enquanto potência liderante do "Mundo Ocidental", a promoção do desenvolvimento integrado nos moldes de um capitalismo regulado por "Estados-Providência" e contando com o apoio do "Plano Marshall"/da OECE, o reforço dos níveis de integração da Europa Ocidental e as virtualidades de regimes demoliberais ou democráticos, o 
reconhecimento do direito à autodeterminação das populações dos "territórios não autónomos" e a negociação de processos de independência.

Crescentemente fragilizado pelas más condições de vida nas zonas rurais e por uma emigração massiva, por contestação estudantil e sindical organizada a partir de Associações de Estudantes e de Sindicatos Nacionais até pouco antes apoiantes da ditadura, pelas guerras coloniais e pelo reforço das oposições, o marcelismo acabou por ser derrubado pelo Golpe Militar de 25 de Abril de 1974, o qual se transformou numa Revolução. Assumindo a forma de mudança revolucionária, mas, também, de transição, superada uma fase de radicalização político-ideológica e socioeconómica à extrema-esquerda e à extrema-direita, a referida etapa culminou na implantação de um regime democrático e na aceitação da independência das ex-colónias, na reprodução de um capitalismo semiperiférico e na ampliação de um "Estado-Providência", na opção de permanecer na NATO e de aderir à CEE (depois UE).

Relativamente ao Brasil, Estado independente desde 1822, será operatório afirmar que continua a tratar-se de uma nação subdesenvolvida, mau grado a evolução verificada nas últimas décadas e o facto de ter passado, quer a ser referenciado como "país emergente", quer a ocupar uma posição mais relevante no âmbito do sistema de relações internacionais do pós "Guerra Fria". Dependeu, ao longo da centúria em causa, sobretudo da Grã-Bretanha (até à Primeira Grande Guerra) e dos EUA (a partir da Segunda Guerra Mundial). Na segunda metade da década de 1930, o Terceiro Reich nacional-socialista reivindicou o direito de substituir ou de partilhar com o Reino Unido e com os EUA a função de liderança à escala global, tendo o Estado Novo de Getúlio Vargas encarado essa possibilidade como uma oportunidade de consolidação interna e de reposicionamento externo. A Argentina e o Chile assumiram o estatuto de rivais e/ou de principais parceiros no contexto imediato da América do Sul.

Depois das mais de seis décadas de regime liberal conservador monárquico conciliável com a manutenção da escravatura, partindo do golpe militar e civil de 15 de Novembro de 1889, foi instaurada uma república demoliberal com traços de autoritarismo e de segregação étnica. Sob a liderança de Getúlio Vargas, entre 1930 e 1945 o Brasil adotou soluções ditatoriais de direita de cariz autoritário e/ou totalitário, nacionalistas, modernizadoras e corporativistas. $\mathrm{Na}$ terminologia da época, muitas vezes assumida pela historiografia, a "República Velha" foi substituída pela "República Nova" e, nesta, pelo autodesignado Estado Novo. No rescaldo da Segunda Guerra Mundial, em 1945 verificou-se a adoção de um regime demoliberal próximo da democracia. Após o interregno resultante da Presidência de Eurico Gaspar Dutra, o mesmo Getúlio Vargas e os 
seus continuadores tardios (João Goulart e, potencialmente, Leonel Brizola) ou outros Chefes de Estado - Juscelino Kubitschek e Jânio Quadros - simbolizaram a concretização de programas políticos de centro-esquerda, muitas vezes catalogados como "desenvolvimentistas" e "trabalhistas" ou "populistas".

Ampliados pela lógica da "Guerra Fria", as dificuldades económico-financeiras e os conflitos de interesses acumulados resultaram, com o apoio e a intervenção direta dos EUA e de outros Estados do "Mundo Livre", no eclodir do Golpe Militar de 1964 e na consolidação de uma ditadura militar-civil de direita de natureza autoritária e/ou totalitária. Considero, assim, ser operatório comparar a ideologia e outras características dos movimentos e dos regimes de tipo fascista - muitas vezes encarados como existentes apenas nas décadas de 1920 a 1940 - com as concretizações imateriais e institucionais ou organizacionais, em países periféricos ou, mesmo, semiperiféricos (americanos, asiáticos, africanos, do Sul da Europa), da norte-americana "Doutrina de Segurança Nacional".

Implantada quase duas décadas depois do fim da "Época do fascismo", enquadrada pelos EUA e por demais países capitalistas desenvolvidos, tendo estabelecido estreitos laços sectoriais de cooperação com outros "regimes de ordem" da América do Sul, a ditadura militar-civil brasileira acarretou diferentes níveis de violência punitiva e preventiva, privação de direitos e aparente pluralismo político; liberalização e crescimento económicos, modernização e aumento das desigualdades sociais; crise económico-financeira e endividamento externo, alienação de apoios internos e externos.

Culminando um multifacetado processo de transição desencadeado em 1974, em 1985 o Brasil configurou um regime democrático que vigora até hoje. Discordo dos estudiosos que põem em causa a natureza no essencial democrática do atual figurino político brasileiro face à reprodução de elevados níveis de desigualdade social e de violência, de corrupção e de nepotismo. Considero que a explicação para tais bloqueios resulta mais de fatores não político-institucionais - os equilíbrios internos e a posição relativa na economia-mundo capitalista, o abstencionismo cívico e o radicalismo ideológico - do que da impossibilidade formal de fazer do sistema político um instrumento de representação proporcional e regulada dos vários interesses sociais e das diversas mundividências.

Diferentemente do sucedido na Europa Ocidental, os projetos de cooperação regional da América do Sul - da América Latina ou do conjunto do continente americano - quase não ultrapassaram, ainda, os níveis superficiais ou da mera retórica política. O predomínio de conceções nacionalistas e, sobretudo, culpabilizadoras do "outro dominador" (Portugal ou Espanha, Grã-Bretanha, 
EUA), limitam, pois, a respetiva capacidade de contribuir para novas configurações do sistema de relações internacionais - mais multipolar e com uma governação acrescidamente multilateral -, para o reforço de regimes políticos democráticos e de estratégias de desenvolvimento integrado e sustentável.

\section{Conclusão}

Penso ter argumentado com coerência que a análise da história da historiografia e das outras ciências sociais partindo das categorias de "paradigma moderno", "paradigma pós-moderno" e "paradigma neo-moderno" permite um acréscimo significativo de operatividade no que concerne à compreensão, quer dos processos de evolução endógena dessas áreas de saber, quer do seu correlacionamento com os respetivos contextos sociais globais. Algo de semelhante terá sido feito no que diz respeito à forma como, em ciências e em tecnologias sociais, encaramos os dilemas decorrentes da relação entre ciência e ideologia, entre objetividade e objetivação, entre conhecer e transformar a realidade.

Defendi, igualmente, por um lado, as vantagens para a historiografia de uma utilização operatória dos conceitos teóricos; por outro, a pertinência de uma determinada tipologia de regimes políticos, aplicável ao estudo da época contemporânea. Esbocei, para terminar, uma tentativa de considerar a evolução política de Portugal e do Brasil, ao longo do século XX, à luz dos referidos modelos. Mais do que salientar excecionalidades e aleatoriedades - quase sempre parcelares e temporárias -, deveríamos, partindo de instrumentos teóricos de utilização universal, estabelecer comparações que viabilizam destacar semelhanças e diferenças, permanências e alterações, características próprias e influências de contexto, condicionalismos estruturais e fatores transitórios.

Tanto acerca da história contemporânea de Portugal como do Brasil, continuam, pois, a ser pertinentes projetos de investigação e de transferência de saber, estratégias de ensino e de divulgação, debates culturais e cívicos, abordagens disciplinares e interdisciplinares, leituras monográficas e comparativas que contribuam para um melhor conhecimento destes e de outros fenómenos. Destaco, nomeadamente, a presença de modalidades institucionais e informais de discriminação tendo em conta critérios de ordem étnica, religiosa e/ou nacional; os condicionalismos explicativos do insucesso de experiências políticas demoliberais e democráticas; a natureza da Primeira República e do Estado Novo portugueses, do Estado Novo e da Ditadura 
Militar-Civil brasileiros; o âmbito e as implicações de processos de transição entre figurinos ditatoriais e soluções que garantem direitos de participação política; as características diferenciadoras de regimes democráticos face a modelos demoliberais.

O pós "Guerra Fria" e a presente conjuntura de dificuldades económico-sociais, mas, também, político-ideológicas (nos planos nacional, inter-regional e global) voltaram, entretanto, a colocar as questões em apreço no centro da atualidade e das preocupações quotidianas de milhões de indivíduos. Essa centralidade torna, pois, mais visível a relevância da produção, da divulgação e da incorporação de conhecimento tão objetivante quanto possível acerca da evolução das comunidades humanas no espaço e no tempo, sobre as modalidades de organização político-institucional vigentes, tanto em Portugal e no Brasil, como nos respetivos espaços geoestratégicos de enquadramento. 